\title{
Patient visiting and the siting of hospitals in rural areas
}

\author{
K. W. CROSS AND R. D. TURNER \\ Department of Social Medicine, University of Birmingham
}

\begin{abstract}
SUMMARY
For a period of one week all visitors to Shropshire patients in geriatric, psychiatric, and subnormality hospitals were asked to give details of their journey to hospital, including the addresses from which they set out. These data, together with those of the patients in hospital that week, were used to examine (1) the effect of distance of the patient's home from hospital upon the frequency of visiting; and (2) the likely consequences of adopting a policy of concentration of all resources at two district general hospitals. Whereas greater distances between home and hospital (up to 20 miles) resulted in little reduction in the frequency of visiting of short-stay (less than six months) geriatric patients and of both short and long-stay psychiatric patients, they resulted in much less frequent visiting of long-stay geriatric patients. The large majority of subnormality patients were in hospitals outside the County; relatively large distances only were involved and it was not possible to examine this issue for these patients. It was concluded that in this predominantly rural area, the provision of all hospital services at two district general hospital sites would, on the whole, greatly reduce distances travelled by visitors to psychiatric patients and to subnormal patients, and would increase distances to geriatric patients. From the point of view of patient visiting there is certainly a case for siting long-stay (over six months) geriatric patients in units near to their homes, and possibly psychiatric and subnormal patients if their homes are at inconvenient distances from the district general hospital.
\end{abstract}

\section{INTRODUCTION}

An objection raised to the concept of siting all hospital services at district general hospitals, as recommended in the Department of Health and Social Security's Report (1969), is that it would increase the distance between patients' homes and hospitals, and so reduce the ease and frequency of visiting. The validity of this belief was examined by McKeown, Cross, and Keating (1971), who, concluded that if all services were provided from district general hospitals the conditions of visiting would be considerably improved in respect of geriatric and psychiatric patients and enormously improved in respect of the subnormal'.

This conclusion was based on the services of a large city, and it cannot be assumed that it would apply in less heavily populated areas. The present paper examines the same issues in a rural county with no large town and only one of moderate size.

\section{Area of STUdy}

The county of Shropshire was chosen for the present study. This is a predominantly rural area with a population of 337,100 . There are five municipal boroughs and urban districts which together contain 123,000 persons, and nine rural districts containing 214,000 people. Shrewsbury (56,200 population) is the only major town in the area at present; a new town is being developed at Telford.

\section{Location of Hospitals}

One large district general hospital is sited on the outskirts of Shrewsbury and a second is planned for Telford. The locations of hospitals and units for long-stay patients (geriatric, psychiatric, and mentally subnormal) from Shropshire are shown in the Figure. A single psychiatric hospital, the county mental hospital, sited just outside Shrewsbury serves the whole area. There are no hospitals within the county for mentally subnormal patients, although a small number of such patients are accommodated in the psychiatric hospital and in one of the geriatric hospitals; the majority are in hospitals for the subnormal in neighbouring counties. There are nine geriatric units within the county (see Figure); units $\mathrm{A}, \mathrm{B}$, and $\mathrm{C}$ are primarily, or to a substantial degree, used for 


\section{RESULTS}

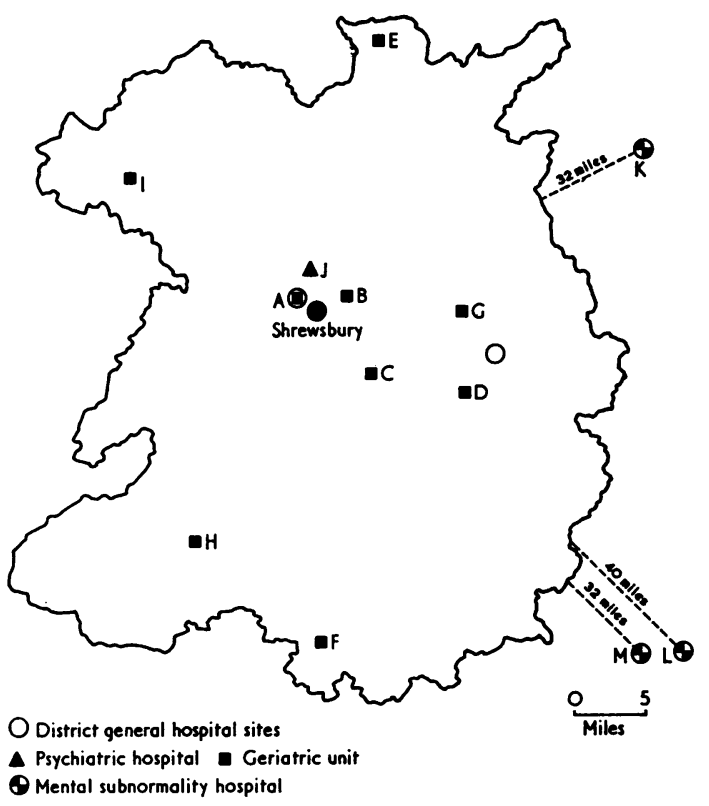

FIoURE. Location of hospitals included in survey. All distances are from Shrewsbury.

assessing the patients' needs and their subsequent rehabilitation, and the remaining units are largely concerned with providing custodial care. The visiting pattern to patients in these units has been the subject of a previous paper (Cross and Turner, 1974).

\section{MethodS}

The methods of data collection were also described in the previous paper. Briefly, a form was completed by every visitor on each visit made during one week (19-25 June 1972) to all patients in the nine geriatric units and in the mental hospital. The survey of visitors to Shropshire patients in two of the hospitals for the mentally subnormal took place during a week in May 1972, and the survey at the third was made during a week in June; at all three hospitals a week was chosen which included a weekend when visitors could be expected (traditionally, at these hospitals, patients are visited on certain weekends during a month). In choosing the weeks of study, care was also taken to avoid state, works or school holidays. After the survey week a form was completed for each patient by recourse to the hospital records.
It is clearly not possible to compare the visiting patterns to patients in units on district general hospital sites with those to patients resident in other units, as was done in the Birmingham study. The approach used in this enquiry is first to establish the extent to which the frequency of visiting is affected by the distance of the patient's home from hospital, and then to examine how the distribution of such distances to existing hospitals compares with the corresponding distributions if all services were concentrated at the two district general hospitals which will ultimately serve the county of Shropshire.

These 'crow-fly' distances were computed from the grid references of the hospitals and of the addresses from which the patients had been admitted to hospital. A small number of patients (most of whom had been in hospital for many years) have been excluded because their addresses were inadequately specified in the records. Those patients who died during the week of the survey have also been excluded because the visiting pattern of these patients was found to be atypical.

\section{Visits to Geriatric Patients}

In the previous paper (Cross and Turner, 1974) we showed that the length of stay of geriatric patients is an important factor determining visiting rates. In order to examine the effect of distance upon visiting rates, results are therefore given separately for short-stay (less than six months) and for long-stay patients (Table I).

Nearly all $(96 \%)$ the short-stay patients were visited during the week and, on the average, eight visits were made per patient. There was little evidence to suggest that visiting rates to short-stay patients decreased as distances increased, and certainly not within the range of 0 to 15 miles. On the other hand, the proportion of long-stay patients who were visited decreased gradually as homehospital distances increased beyond 10 miles. The mean visiting rate decreased more rapidly beyond this distance; the mean number of visits for patients whose homes were more than 15 miles from hospital was only half that for patients whose homes were within 10 miles of hospital.

The consequences, in terms of distance between patient's home and hospital, of concentrating all geriatric services on the two district general hospital sites are evident from Table II. For short-stay patients the proportions who had homes at distances exceeding 5,10 , or 20 miles from the hospitals in which they were accommodated were 
TABLE I

GERIATRIC UNITS: EFFECT OF DISTANCES BETWEEN PATIENTS' HOMES AND HOSPITAL UPON FREQUENCY OF VISITING

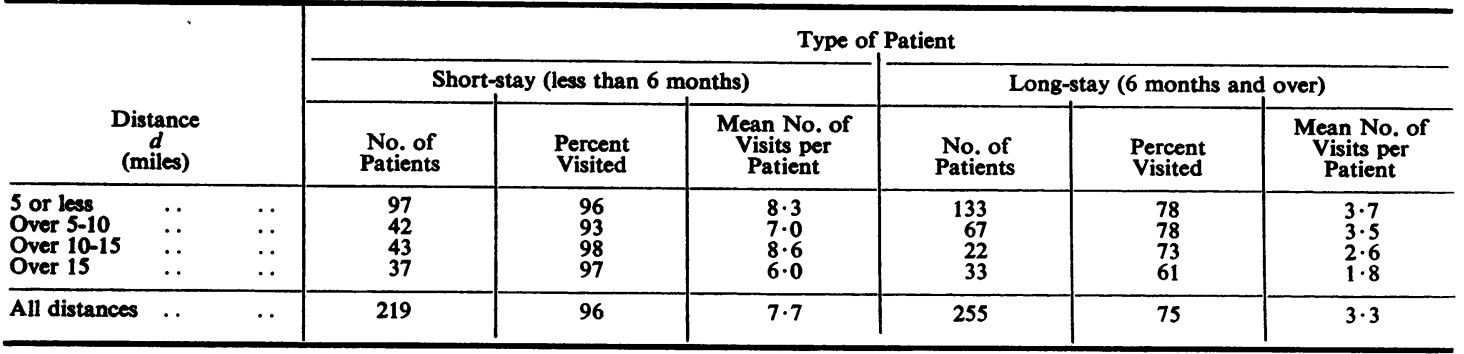

TABLE II

PERCENTAGE OF GERIATRIC PATIENTS WITH HOMES AT DISTANCES EXCEEDING $d$ MILES FROM (i) EXISTING HOSPITAL AND (ii) NEARER DISTRICT GENERAL

\begin{tabular}{c|c|c|c|c} 
& \multicolumn{2}{|c|}{ GENERAL HOSPITAL } \\
\hline \multirow{2}{*}{$\begin{array}{c}\text { Distance } \\
d \\
\text { (miles) }\end{array}$} & \multicolumn{2}{|c|}{$\begin{array}{c}\text { Short-stay } \\
\text { (less than 6 months) }\end{array}$} & \multicolumn{2}{c}{$\begin{array}{c}\text { Long-stay } \\
\text { (6 months and over) }\end{array}$} \\
\cline { 2 - 5 } & (i) & (ii) & (i) & (ii) \\
\hline & & & 48 & 69 \\
$>15$ & 56 & 59 & 48 & 49 \\
$>15$ & 17 & 26 & 23 & 35 \\
$>20$ & 8 & 10 & 6 & 13 \\
\hline
\end{tabular}

similar to the corresponding proportions whose homes were greater than these distances from the nearer district general hospital site. In contrast, for long-stay patients there were sizeable differences between the corresponding proportions for the distances quoted. For example, only $22 \%$ of home to existing hospital distances exceeded 10 miles, as compared with $49 \%$ of patients with homes which were greater than this distance from the nearest district general hospital; and the corresponding proportions for distances exceeding 15 miles were $13 \%$ and $35 \%$.

\section{Visits to Psychiatric Patients}

There were 512 Shropshire patients resident in the county mental hospital (hospital J) excluding those classified as mentally subnormal. Four wards in the hospital are termed 'short-stay', and results for patients on these wards are shown separately from those for patients on other wards in Table III; 33 long-stay patients with 'inadequate' addresses were excluded from the analysis.

Two-thirds of the patients on the short-stay wards were visited during the week. The proportion visited varied little with distance over the range 0 to 20 miles, and the same was true of both the mean number of visits per patient and the mean per patient visited. Lower values of these indices were obtained for the patients with home addresses greater than 20 miles from the hospital, but the number of patients was small.

Only one-quarter of the patients on long-stay wards were visited, and there was little evidence to suggest that the proportion visited decreased with distance over the range 0 to 20 miles; but only $15 \%$ of patients with homes more than 20 miles from the hospital were visited. For those long-stay

TABLE III

PSYCHIATRIC UNIT: EFFECT OF DISTANCES BETWEEN PATIENTS' HOMES AND HOSPITAL UPON THE FREQUENCY OF VISITING

\begin{tabular}{|c|c|c|c|c|c|c|c|c|c|}
\hline \multirow{3}{*}{\multicolumn{2}{|c|}{$\begin{array}{c}\text { Distance } \\
\text { d } \\
\text { (miles) }\end{array}$}} & \multicolumn{8}{|c|}{ Type of Ward } \\
\hline & & \multicolumn{4}{|c|}{ Short-stay } & \multicolumn{4}{|c|}{ Long-stay } \\
\hline & & $\begin{array}{c}\text { No. of } \\
\text { Patients }\end{array}$ & $\begin{array}{l}\text { Percent } \\
\text { Visited }\end{array}$ & $\begin{array}{c}\text { Mean No. of } \\
\text { Visits per } \\
\text { Patient }\end{array}$ & \begin{tabular}{|c|} 
Mean No. of \\
Visits per \\
Patients \\
Visited
\end{tabular} & $\begin{array}{l}\text { No. of } \\
\text { Patients }\end{array}$ & $\begin{array}{l}\text { Percent } \\
\text { Visited }\end{array}$ & $\begin{array}{c}\text { Mean No. of } \\
\text { Visits per } \\
\text { Patient }\end{array}$ & $\begin{array}{l}\text { Mean No. of } \\
\text { Visits per } \\
\text { Patients } \\
\text { Visited }\end{array}$ \\
\hline $\begin{array}{l}\text { or less } \\
\text { Over 5-10 } \\
\text { Over 10-15 } \\
\text { Over 15-20 } \\
\text { Over } 20\end{array}$ & $\begin{array}{l}. . \\
\because \\
\because \\
\therefore\end{array}$ & $\begin{array}{r}23 \\
8 \\
24 \\
31 \\
10\end{array}$ & $\begin{array}{c}74 \\
(63) \\
67 \\
68 \\
(50)\end{array}$ & $\begin{array}{c}1 \cdot 8 \\
(0 \cdot 8) \\
2 \cdot 0 \\
1.9 \\
(0.9)\end{array}$ & $\begin{array}{c}2 \cdot 5 \\
(1 \cdot 2) \\
2 \cdot 9 \\
2 \cdot 8 \\
(1 \cdot 8)\end{array}$ & $\begin{array}{r}78 \\
24 \\
119 \\
114 \\
48\end{array}$ & $\begin{array}{l}29 \\
29 \\
24 \\
29 \\
15\end{array}$ & $\begin{array}{l}0.4 \\
0.3 \\
0.5 \\
0.5 \\
0.25\end{array}$ & $\begin{array}{l}1.3 \\
1.1 \\
2.0 \\
1.8 \\
1.7\end{array}$ \\
\hline All distances & $\ldots$ & 96 & 67 & 1.7 & $2 \cdot 5$ & 383 & 26 & 0.4 & 1.7 \\
\hline
\end{tabular}

Figures in parentheses are based upon small numbers of patients. 
patients who were visited, the mean number of visits per patient did not significantly vary over the whole range of distance here considered.

Since there is only one psychiatric unit in the county at present, it is not surprising that the provision of psychiatric units at the two district general hospital sites would, on the whole, significantly reduce distances between patients' homes and hospital (see Table IV). About two-thirds of

TABLE IV

PERCENTAGE OF PSYCHIATRIC PATIENTS WITH HOMES AT DISTANCES EXCEEDING $d$ MILES FROM (i) EXISTING HOSPITAL AND (ii) NEARER DISTRICT GENERAL HOSPITAL

\begin{tabular}{c|c|c|c|c}
\hline \multirow{2}{*}{$\begin{array}{c}\text { Distance } \\
\begin{array}{c}d \\
\text { (miles) }\end{array}\end{array}$} & \multicolumn{2}{|c|}{$\begin{array}{c}\text { Patients on Short- } \\
\text { stay Wards }\end{array}$} & \multicolumn{2}{|c}{$\begin{array}{c}\text { Patients on Other } \\
\text { Wards }\end{array}$} \\
\cline { 2 - 5 } & (i) & (ii) & (i) & (ii) \\
\hline & & & & \\
$>5$ & 76 & 56 & 80 & 59 \\
$>10$ & 68 & 36 & 73 & 34 \\
$>15$ & 43 & 23 & 42 & 20 \\
$>20$ & 10 & 8 & 12 & 9 \\
\hline
\end{tabular}

the patients on short-stay wards had home addresses at distances greater than 10 miles from the existing hospital, whereas the corresponding proportion in relation to the nearer of the district general hospital sites was about one-third. The same order of difference $(2: 1)$ applies in respect of proportions referable to distances exceeding 15 miles. Similar results were obtained for patients on longstay wards.

\section{Visits to Mentally Subnormal Patients}

There were 18 Shropshire patients at the mental hospital (J) and 22 patients at the predominantly geriatric hospital (unit D) who were classed as mentally subnormal. All 40 patients had been in hospital for several years, and in fact only one patient (at unit D) was visited.

Of the 144 Shropshire patients who were accommodated in the three hospitals for the mentally subnormal outside the county, $32(22 \%)$ were visited. On the average, each patient visited received two visitors. Most of the patients had been in hospital for some years and had home addresses which were more than 15 miles from hospital. It was therefore not possible to examine whether the frequency of visiting was related to distance or to length-of-stay.

It is obvious that the provision of accommodation for all mentally subnormal patients within the county would greatly reduce the inconvenience caused to visitors, and if facilities were provided at the two district general hospital sites there would be a dramatic reduction in distances to be travelled. The considerable inconvenience to which visitors are at present subjected was evident from this study: virtually all the visitors travelled by car, and the mean travelling time for the one-way journey was 70 minutes.

\section{Discussion}

The analysis of visits made to Shropshire patients in geriatric units clearly demonstrated that, whereas greater distances between home and hospital result in very little reduction in the frequency of visiting of short-stay patients, they result in much less frequent visiting of long-stay patients. Furthermore, on the whole, these distances for long-stay patients would be considerably increased if all geriatric facilities were located at the two district general hospital sites, since existing units for long-stay patients are distributed throughout the county (see Figure).

The results of this survey therefore suggest that, from the standpoint of patient visiting, long-stay geriatric patients in a predominantly rural area should be accommodated in hospitals near to the communities where their relatives and friends reside; and, in the case of Shropshire, concentration of all geriatric facilities on the two district general hospital sites would be likely to reduce the level of visiting. Moreover, it is difficult to see how a system of day-care for geriatric patients can be operated unless such units are sited so that elderly people who need care and atcention during the day can easily be transported to them.

The situation regarding psychiatric patients is quite different in that, as is true of many rural areas, one mental hospital at present serves the population of the whole county. The majority of patients are long-stay (over two years in continuous residence) who are infrequently visited; and, up to 20 miles, distance between home and hospital appears to have little effect upon visiting rates. This population will not be replaced as it declines due to death, and meantime those patients remaining will probably stay at the mental hospital, regardless of what facilities are provided at the two district general hospital sites. Even if they were transferred it is doubtful whether they would be visited more frequently than at present. As regards psychiatric patients on the short-stay wards, there is again little evidence to suggest that greater distances between home and hospital (up to 20 miles) result in less frequent visiting; but in any 
case the provision of two units at the district general hospital sites would, on the whole, result in shorter distances.

In the case of the mentally subnormal patients who are nearly all in hospitals outside the county, there was no basis for assessing how the frequency of visiting is affected by distances travelled by visitors. The average time now taken by visitors in making the return journey is two hours and twenty minutes, and obviously this would be considerably reduced if patients were accommodated on the two district general hospital sites. Although the depressingly low figure for the proportion of patients visited during a week cannot be attributed wholly to the location of hospitals, it can hardly be doubted that to some extent it reflects the formidable journeys now involved.

We conclude, therefore, that in this county provision of all hospital services at the two district general hospital sites would greatly reduce distances travelled by visitors to psychiatric patients and to subnormal patients, and would increase distances to geriatric patients. From this point of view there is certainly a case for siting in units near to their homes long-stay geriatric patients, and possibly psychiatric and subnormal patients if their homes are at inconvenient distances from the district general hospital. However, ease of visiting is only one of the issues to be considered in relation to hospital siting, although it is an important one. It should also be stressed that these considerations apply only in thinly populated areas, and there are no corresponding grounds for fragmentation of hospital services in large urban areas.

We are indebted to the nursing staffs and administrators of the Shropshire hospitals; and to Miss Ida Giles and Mrs. Betty Mann, who assisted with the collection and processing of the data. Our thanks are also due to Mr. R. Lancaster and Mrs. Angela Henze for writing the computer programs.

\section{REFERENCES}

McKeown, T., Cross, K. W., and Keating, D. M• (1971). Influence of hospital siting on patient visiting. Lancet, 2, 1082.

Cross, K. W. and Turner, R. D. (1974). Factors affecting the visiting pattern of geriatric patients in a rural area. Brit. J. prev. soc. Med., 28, 133.

Department of Health and Social Security (1969). The Functions of the District General Hospital. HMSO, London. 